ARTICLE

https://doi.org/10.1038/s41467-019-08763-4

\title{
3D ink-extrusion additive manufacturing of CoCrFeNi high-entropy alloy micro-lattices
}

\author{
Christoph Kenel (1) ${ }^{1}$, Nicola P.M. Casati (iD ${ }^{2} \&$ David C. Dunand (D) ${ }^{1}$
}

Additive manufacturing of high-entropy alloys combines the mechanical properties of this novel family of alloys with the geometrical freedom and complexity required by modern designs. Here, a non-beam approach to additive manufacturing of high-entropy alloys is developed based on $3 \mathrm{D}$ extrusion of inks containing a blend of oxide nanopowders $\left(\mathrm{CO}_{3} \mathrm{O}_{4}+\right.$ $\mathrm{Cr}_{2} \mathrm{O}_{3}+\mathrm{Fe}_{2} \mathrm{O}_{3}+\mathrm{NiO}$ ), followed by co-reduction to metals, inter-diffusion and sintering to near-full density $\mathrm{CoCrFeNi}$ in $\mathrm{H}_{2}$. A complex phase evolution path is observed by in-situ X-ray diffraction in extruded filaments when the oxide phases undergo reduction and the resulting metals inter-diffuse, ultimately forming face-centered-cubic equiatomic CoCrFeNi alloy. Linked to the phase evolution is a complex structural evolution, from loosely packed oxide particles in the green body to fully-annealed, metallic CoCrFeNi with $99.6 \pm 0.1 \%$ relative density. CoCrFeNi micro-lattices are created with strut diameters as low as $100 \mu \mathrm{m}$ and excellent mechanical properties at ambient and cryogenic temperatures.

\footnotetext{
${ }^{1}$ Department of Materials Science and Engineering, McCormick School of Engineering, Northwestern University, Evanston, IL 60208, USA. ${ }^{2}$ Swiss Light Source, Paul Scherrer Institut, 5232 Villigen, Switzerland. Correspondence and requests for materials should be addressed to C.K. (email: Christoph. Kenel@northwestern.edu)
} 
abrication of engineering parts from high-entropy alloys (HEA) using additive manufacturing (AM) has been increasingly studied in the past five years ${ }^{1-3}$. Initial studies focused on powder bed fusion of $\mathrm{CoCrFeNi}$, a prototype singlephase high entropy alloy with face-centered-cubic (fcc) structure $^{4}$, from pre-alloyed powders, and observed increased strength and ductility compared to cast alloys ${ }^{3}$. Later, the Al-Co-Cr-Fe-Ni system was predominantly studied, either as equiatomic $\mathrm{AlCoCrFeNi}$ or as $\mathrm{Al}_{\mathrm{x}} \mathrm{CoCrFeNi}$ with $0.1<\mathrm{x}<1^{5-9}$. Other work demonstrated AM of CoCrFeMnNi by selective laser melting ${ }^{10}$, $\mathrm{Co}_{1.5} \mathrm{CrFeNi}_{1.5} \mathrm{Ti}_{0.5} \mathrm{Mo}_{0.1}$ by directed energy deposition ${ }^{5}$, ZrTiVCrFeNi by electron beam melting ${ }^{11}$, and polymerAlCoCrFeNi composites by coating $260 \mathrm{~nm}$ thick 3D printed polymer nanolattices with $14-126 \mathrm{~nm}$ thick HEA shells ${ }^{12}$. It is typically observed that AM processing through the liquid state, followed by solidification at high cooling rates, refines the grain size, leads to finer precipitates in two-phase alloys, and produces a highly textured microstructure; however, it may require high preheating temperatures to attenuate cracking, and it leads to inter-dendritic segregation of elements and microstructural gradients due to the imposed thermal history in the layer-wise process $^{5}$. Apart from the currently dominating laser- and electron-beam based AM methods, alternative methods to metal AM have been developed, such as binder jetting ${ }^{13-17}$ and 3D inkextrusion printing ${ }^{18}$ where first a binder-containing green body is shaped at ambient temperature from elemental or pre-alloyed powders that is then densified in a subsequent isothermal sintering step. These techniques have the potential to provide segregation-free, structurally-homogeneous alloys with low residual stress due to full inter-diffusion and isothermal sintering, while also reducing cost and eliminating the need of inert-gas processing environments of beam-based AM. The inks for 3D inkextrusion can be produced from alloyed metal powder, elemental powder or compounds that reduce (e.g., oxides) or decompose (e.g., hydrides) to metal upon thermal processing ${ }^{18-27}$. The elimination of pre-alloying steps (i.e., to create powders for selective laser melting) and the ability to directly produce alloys from blended pure oxide feedstock further reduce cost, time, and provide full flexibility of alloy composition. The use of oxides is limited to those which can be reduced with gases, such as $\mathrm{CO}$ or $\mathrm{H}_{2}$. Under hydrogen, pressed $\mathrm{Cr}_{2} \mathrm{O}_{3}$ pellets require $18 \mathrm{~h}$ at $1373 \mathrm{~K}$ for full reduction, making this approach unpractical for commercial production of pure $\mathrm{Cr}$ metal ${ }^{28}$. For alloyed systems, sequential reduction was observed upon co-reduction of $\mathrm{Fe}_{2} \mathrm{O}_{3}+$ $\mathrm{NiO}^{29}$ and $\mathrm{Co}_{3} \mathrm{O}_{4}+\mathrm{NiO}^{30}$ powder blends, with metallic $\mathrm{Ni}$ forming first. Synergistic effects have been found in co-reduced $\mathrm{FeCr}_{2} \mathrm{O}_{4}{ }^{31,32}$ (or $\mathrm{CoCr}_{2} \mathrm{O}_{4}{ }^{33}$ ) powders, where first a Fe (or Co-) matrix, is formed which then acts as an acceptor for reduced $\mathrm{Cr}$ atoms creating a $\mathrm{Fe}-\mathrm{Cr}$ (or $\mathrm{Co}-\mathrm{Cr}$ ) alloy. Co-reduction of blended $\mathrm{Fe}_{2} \mathrm{O}_{3}+\mathrm{NiO}+\mathrm{Cr}_{2} \mathrm{O}_{3}$ powders was found to proceed as a combination of the binary sub-systems: metallic Ni forms first, then forming $\mathrm{Ni}-\mathrm{Fe}$ solid solutions and gradually incorporating $\mathrm{Cr}$ until a Ni-Fe-Cr alloy is achieved ${ }^{34}$. Using this approach, complex alloys, such as martensitic and maraging steels, can be produced from blended oxide precursors ${ }^{35-37}$ : for example, honeycomb $\mathrm{Fe}$ $\mathrm{Ni}$ and $\mathrm{Fe}-\mathrm{Cr}$ structures have been manufactured via extrusion of blended $\mathrm{Fe}_{2} \mathrm{O}_{3}+\mathrm{NiO}$ and $\mathrm{Fe}_{2} \mathrm{O}_{3}+\mathrm{Cr}_{2} \mathrm{O}_{3}$ slurries followed by reduction in $\mathrm{H}_{2}{ }^{37,38}$.

In this work, we demonstrate an approach to AM of HEAs by $3 \mathrm{D}$ extrusion printing of inks containing a blend of $\mathrm{Co}_{3} \mathrm{O}_{4}+$ $\mathrm{Cr}_{2} \mathrm{O}_{3}+\mathrm{Fe}_{2} \mathrm{O}_{3}+\mathrm{NiO}$ nanometric powders, followed by coreduction and sintering to yield equiatomic $\mathrm{Co}-\mathrm{Cr}-\mathrm{Fe}-\mathrm{Ni}$, a prototype alloy for single-phase fcc high entropy alloys ${ }^{4}$. We study the phase and microstructural evolution throughout thermal processing, from extrusion-printed oxide to fully-densified HEA filaments. A fcc CoCrFeNi HEA is obtained with near-full density $(0.4 \pm 0.1 \%$ porosity) and a minimal feature size (filament diameter) of $100 \mu \mathrm{m}$. In situ X-ray diffraction, together with thermogravimetry, reveal the kinetics of reduction and interdiffusion upon thermal processing, starting from loosely-packed, as-printed oxide powders to freshly-reduced metallic particles, with sub-micrometer size which is crucial in rapidly achieving near-full densities. Mechanical testing of sintered single filaments and micro-lattices show an excellent combination of ductility and strength at ambient and cryogenic temperatures.

\section{Results and discussion}

3D ink-extrusion, reduction, and sintering of CoCrFeNi HEA. The ink used for 3D ink-extrusion consists of a blend of $\mathrm{Co}_{3} \mathrm{O}_{4}$, $\mathrm{Cr}_{2} \mathrm{O}_{3}, \mathrm{Fe}_{2} \mathrm{O}_{3}$, and $\mathrm{NiO}$ powders, poly-lactic-co-glycolic-acid as binder, dibutyl phthalate as plasticizer, and ethylene glycol butyl ether as a surfactant. Thermogravimetric analysis (TGA) in $\mathrm{a}_{2}$ atmosphere of the blended oxide powders without binder shows reduction in two major steps (Fig. 1). First, the metals $\mathrm{Co}, \mathrm{Fe}$, and $\mathrm{Ni}$ are formed in rapid succession, leading to a mass loss of $20.5 \%$, close to the theoretical stoichiometric value of $19.7 \%$. In a second step - and with a roughly tenfold slower mass loss rate-the more stable $\mathrm{Cr}_{2} \mathrm{O}_{3}$ is reduced to $\mathrm{Cr}$, which diffuses into the adjacent Co-Fe-Ni matrix, increasing its $\mathrm{Cr}$ content. The final mass loss after holding under $\mathrm{H}_{2}$ for $1 \mathrm{~h}$ at $1557 \mathrm{~K}$ is measured at $28.3 \%$, in good agreement with the theoretical value of $27.5 \%$. The oxide powders, blended using wet mill-mixing, show $<10 \mu \mathrm{m}$ agglomerates and $\mathrm{a}<1 \mu \mathrm{m}$ grain size, enabling a large surface area and the observed fast initial reaction with $\mathrm{H}_{2}$ (Fig. 1b). The small agglomerate size is also crucial for $3 \mathrm{D}$ extrusion printing with fine nozzles without clogging. X-ray diffraction of the blended oxide powder prior and after the TGA measurement demonstrates the structural change from blended oxides to a single-phase fcc CoCrFeNi HEA with no oxide diffraction rings left (Fig. 1c). This clearly illustrates the feasibility of creating HEA from blended oxide powder feedstock and provides the base for 3D inkextrusion of complex HEA objects. The ink for 3D ink-extrusion is mill-mixed and thickened for the shape-defining first step (Fig. 1d, top). This defines the architecture and geometrical relations of the part. In a second step, the blended oxide is converted to metallic CoCrFeNi HEA by co-reduction, interdiffusion and sintering in $\mathrm{H}_{2}$ atmosphere. Despite the drastic changes in material properties from an oxide-polymer composite to a fully-annealed, densified, metallic CoCrFeNi HEA and the associated mass $(-40 \%)$ and volume changes $(-78 \%)$, the architecture of the micro-lattice is fully conserved without warping or cracking, due to isotropic and homogeneous shrinkage (Fig. 1d, bottom). The extensive but uniform shrinkage has the advantage to allow the creation of features (i.e., struts) with diameters below that of the extrusion nozzle used. In the example shown here, printing was performed with a $200 \mu \mathrm{m}$ diameter nozzle, resulting in a HEA strut diameter of $103 \mu \mathrm{m}$.

Phase evolution by in situ synchrotron $\mathrm{X}$-ray diffraction. A detailed analysis of the phase evolution of $250 \mu \mathrm{m}$ diameter extruded filaments including the binder during co-reduction is performed using in situ synchrotron X-ray diffraction (XRD) in flowing $\mathrm{H}_{2}$ (Fig. 2). The as-printed filament shows only the expected peaks for the $\mathrm{Co}_{3} \mathrm{O}_{4}, \mathrm{Cr}_{2} \mathrm{O}_{3}, \mathrm{Fe}_{2} \mathrm{O}_{3}$, and $\mathrm{NiO}$ powder (Fig. 2a). After in situ co-reduction, a fcc CoCrFeNi HEA is observed, with a lattice constant of $3.575( \pm 0.002)$ and 3.6468 $( \pm 0.0004) \AA$ at 293 and $1215 \mathrm{~K}$, respectively. The average coefficient of thermal expansion, calculated as $21.6 \pm 0.5 \times 10^{-6} \mathrm{~K}^{-1}$, is in general agreement with the scarce literature values available from linear expansion measurements of bulk specimens ${ }^{39,40}$. Detailed peak analysis reveals the presence of two fcc phases with 
a

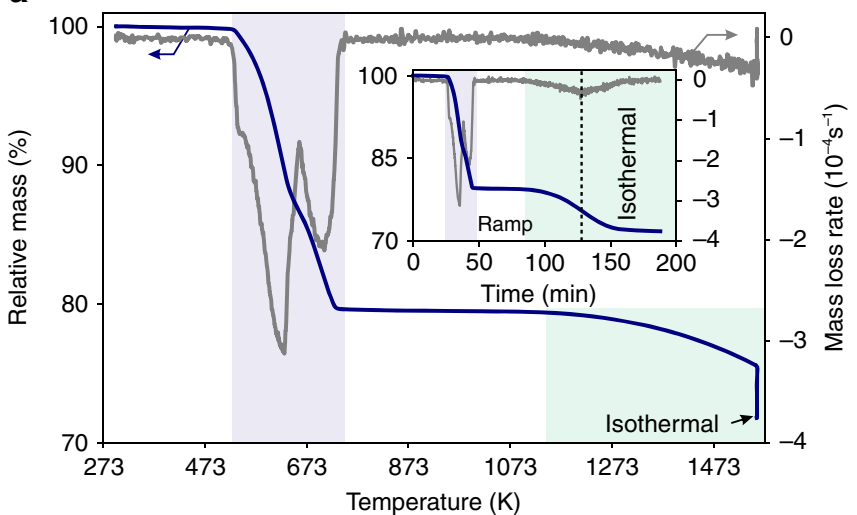

b

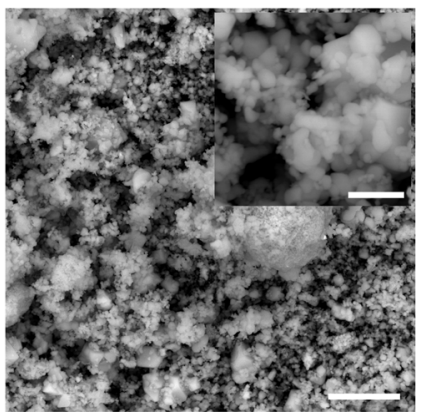

C

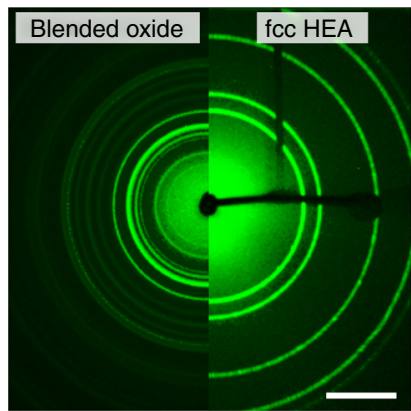

d

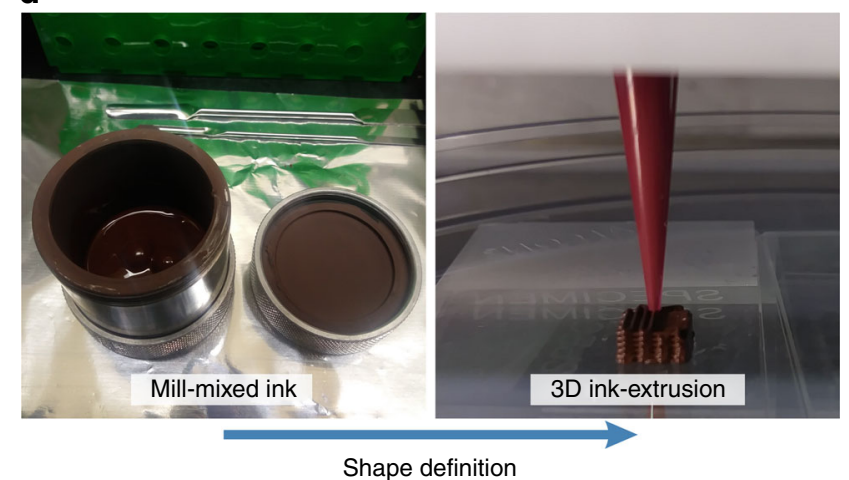

CO-reduction, interdiffusion and sintering

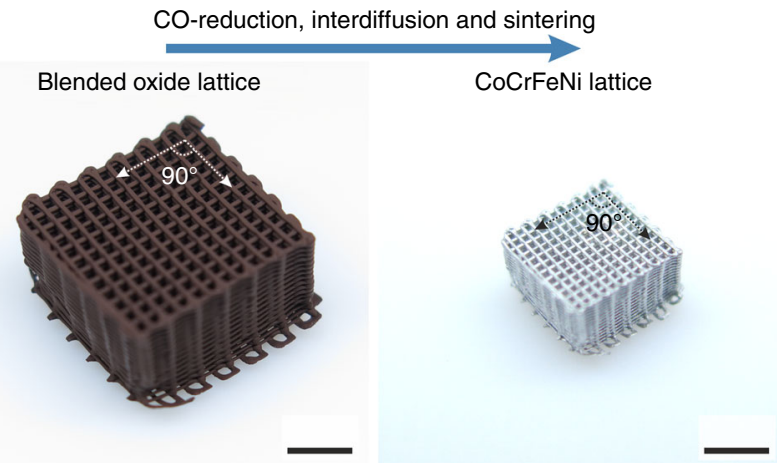

Fig. 1 Creating CoCrFeNi high-entropy alloys via 3D ink-extrusion, reduction and sintering of oxide powder blends. a TGA mass loss of a loose blend of $\mathrm{CO}_{3} \mathrm{O}_{4}+\mathrm{Cr}_{2} \mathrm{O}_{3}+\mathrm{Fe}_{2} \mathrm{O}_{3}+\mathrm{NiO}$ as function of temperature in a $\mathrm{H}_{2}$ atmosphere. Initial reduction of $\mathrm{Co}_{3} \mathrm{O}_{4}$, $\mathrm{Fe}_{2} \mathrm{O}_{3}$ and $\mathrm{NiO}$ (blue shading) is followed by reduction of $\mathrm{Cr}_{2} \mathrm{O}_{3}$ (green shading). Inset: Same data as function of time, showing ramp and $1 \mathrm{~h}$ hold at $1557 \mathrm{~K}$, when continuous mass loss occurs due to ongoing reduction of $\mathrm{Cr}_{2} \mathrm{O}_{3}$ until it is fully consumed. b Scanning electron micrograph of the blended oxide powder prior to TGA, showing agglomerate sizes $<10 \mu \mathrm{m}$ and sub-micron particle size. Scale bars are $5 \mu \mathrm{m}$ and $1 \mu \mathrm{m}$ (inset). c Combined 2D diffractograms of blended oxide prior (left) and after (right) the TGA measurement in $\mathrm{H}_{2}$ showing the complete disappearance of all oxide-related diffraction intensities and formation of a face-centered cubic CoCrFeNi HEA. Scale bar is $20 \mathrm{~nm}^{-1}$. d The two-step processing route first shapes the mill-mixed ink using 3D ink-extrusion into the desired architecture (a micro-lattice with $200 \mu \mathrm{m}$ diameter struts, in the present example). In a second step, the powders in the green body are co-reduced, inter-diffused and sintered to yield a CoCrFeNi HEA micro-lattice with much smaller overall dimensions and strut diameter, without warping or cracking. Scale bars are 3 mm

a difference of $2.6 \times 10^{-3} \AA$ in their lattice spacings (Supplementary Figure 1). While this peak doublet could reflect incomplete inter-diffusion and homogenization, other high resolution X-ray diffraction studies have produced similar results on as-cast and homogenized $\mathrm{CoCrFeNi}$, indicating that many high-entropy alloys might consist of multiple, closely-related structures with the same symmetry ${ }^{41}$. Upon oxide co-reduction, the rapid sequential formation of metallic $\mathrm{Co}, \mathrm{Ni}$ and $\mathrm{Fe}$ is observed while $\mathrm{Cr}_{2} \mathrm{O}_{3}$ persist until its slow reduction above $1073 \mathrm{~K}$ (Fig. 2b), in agreement with the TGA results. The faster reduction of $\mathrm{Cr}_{2} \mathrm{O}_{3}$ in the in situ XRD experiment compared to the TGA is explained by the faster $\mathrm{H}_{2}$ flow conditions in the capillary setup and the higher purity of the $\mathrm{H}_{2}$ gas $(6 \mathrm{~N}$ vs. $5 \mathrm{~N})$, effectively lowering the local $\mathrm{O}_{2}$ partial pressure. The complexity of the phase evolution upon coreduction is illustrated in Fig. 2c. Initial sequential reduction of $\mathrm{NiO}$ to fcc $\left(\mathrm{Ni}\right.$ ), of $\mathrm{Fe}_{2} \mathrm{O}_{3}$ to $\mathrm{Fe}_{3} \mathrm{O}_{4}$ to body centered cubic (bcc) $\mathrm{Fe}$, and of $\mathrm{Co}_{3} \mathrm{O}_{4}$ to fine grained hexagonal close packed (hcp) Co with inter-dispersed stable $\mathrm{Cr}_{2} \mathrm{O}_{3}$ occurs within a narrow temperature window, between 573 and $673 \mathrm{~K}$. At higher temperature, the $\mathrm{hcp}(\mathrm{Co})$ transforms to $\mathrm{fcc}(\mathrm{Co})$ and inter-diffusion leads to the formation of additional $\mathrm{fcc}(\mathrm{Fe}, \mathrm{Ni})$ and $\mathrm{bcc}(\mathrm{Co}, \mathrm{Fe})$ phases. With the onset of $\mathrm{Cr}_{2} \mathrm{O}_{3}$ reduction at $1073 \mathrm{~K}$, a fourth fcc phase appears, consuming all other phases and becoming the final fcc CoCrFeNi HEA phase. This phase then remains stable upon cooling back to room temperature, allowing the determination of the above coefficient of thermal expansion (Supplementary Figure 2).
Densification and mechanical performance of CoCrFeNi HEA. Microstructure and integrity of additively-manufactured HEA material are crucial for load-bearing applications. The structural evolution upon co-reduction and sintering is studied in detail on single filaments (Fig. 3). In the as-extruded state, the powder particles are loosely packed in the solidified ink and held together by the binder. Upon de-binding and initial reduction of $\mathrm{Co}_{3} \mathrm{O}_{4}$, $\mathrm{Fe}_{2} \mathrm{O}_{3}$, and $\mathrm{NiO}$ (to $\mathrm{Co}, \mathrm{Fe}$, and $\mathrm{Ni}$, respectively) up to $765 \mathrm{~K}$, this loose particle arrangement is conserved (Fig. 3, top). The presence of unreduced $\mathrm{Cr}_{2} \mathrm{O}_{3}$ reduces the number of contact points between reduced, metallic particles, thus acting as a sintering inhibitor. Larger agglomerates, undergoing local sintering as well as volume reduction of larger oxide particles via chemical reduction, lead to the formation of porous, spongy $\mathrm{Co}$, and $\mathrm{Ni}$. Above $1073 \mathrm{~K}$, fine $\mathrm{Cr}_{2} \mathrm{O}_{3}$ particles reduce to metallic $\mathrm{Cr}$, which then diffuses into, and alloys with, the surrounding porous metal matrix (Supplementary Figure 3). Remaining larger $\mathrm{Cr}_{2} \mathrm{O}_{3}$ particles continue to inhibit densification locally, effectively acting as diffusion barriers. Sintering of the metallic matrix around these micrometer-sized remaining $\mathrm{Cr}_{2} \mathrm{O}_{3}$ particles lead to their encapsulation which strongly hinders access of $\mathrm{H}_{2}$ and removal of $\mathrm{H}_{2} \mathrm{O}$ (Fig. 3, center). Final reduction of remaining $\mathrm{Cr}_{2} \mathrm{O}_{3}$ particles and densification to a near-fully dense state is achieved after sintering at $1573 \mathrm{~K}$ (Fig. 3, bottom). The obtained microstructure exhibits equiaxed grains, 5 to $25 \mu \mathrm{m}$ in size, containing annealing twins; this is a microstructure also observed in cast and recrystallized fcc $\mathrm{CoCrFe}(\mathrm{Mn}) \mathrm{Ni} \mathrm{HEAs}^{42}$. This similarity in 
a

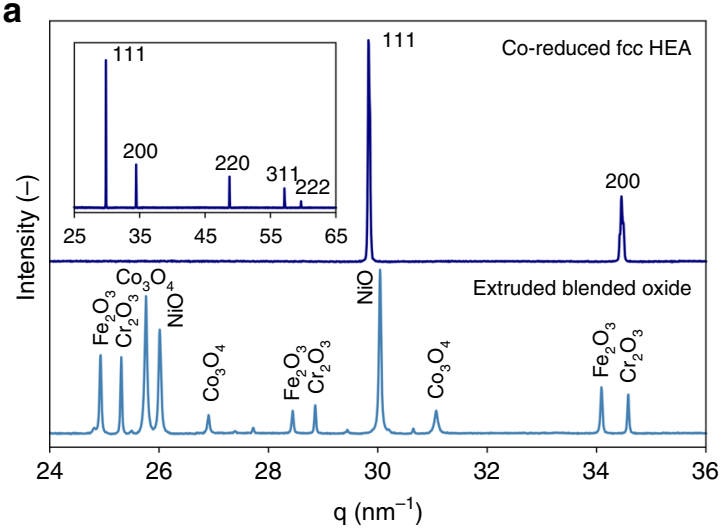

b

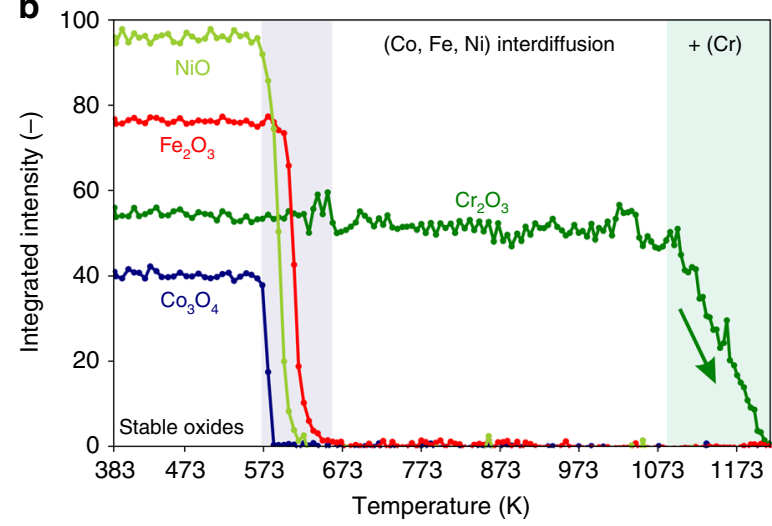

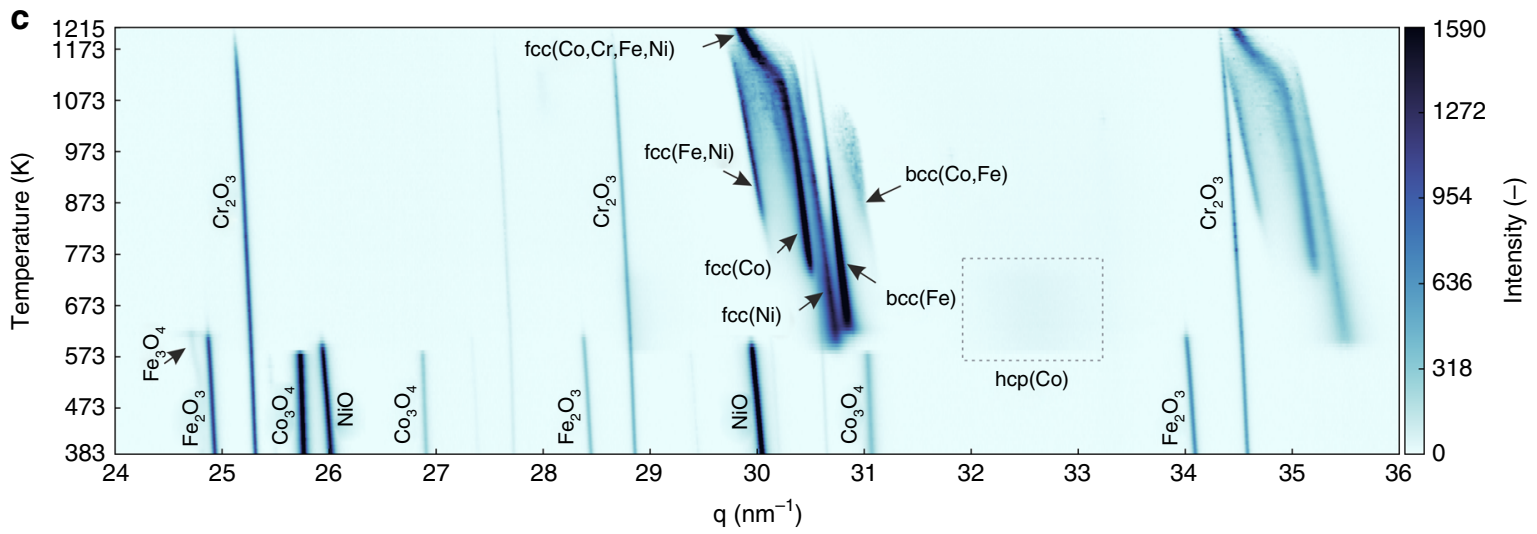

Fig. 2 Phase evolution upon co-reduction of 3D printed blended oxides by in-situ synchrotron XRD in $\mathrm{H}_{2}$. a XRD diffractograms of a $250 \mu \mathrm{m}$ diameter filament extruded from blended $\mathrm{Co}_{3} \mathrm{O}_{4}+\mathrm{Cr}_{2} \mathrm{O}_{3}+\mathrm{Fe}_{2} \mathrm{O}_{3}+\mathrm{NiO}$ inks (bottom) and the inter-diffused fcc HEA filament after completion of the co-reduction step (top). Inset: full data range of the fcc $\mathrm{HEA}$ alloy. $\mathbf{b}$ Evolution of the integrated peak intensities for $\mathrm{Co}_{3} \mathrm{O}_{4}, \mathrm{Cr}_{2} \mathrm{O}_{3}, \mathrm{Fe}_{2} \mathrm{O}_{3}$, and $\mathrm{NiO}$, demonstrating sequential reduction forming $\mathrm{Co}, \mathrm{Ni}$, Fe between 573 and $637 \mathrm{~K}$, followed by reduction of $\mathrm{Cr}_{2} \mathrm{O}_{3}$ between 1073 and $1215 \mathrm{~K}$. c $2 \mathrm{D}$ phase evolution plot (temperature vs. the scattering vector q, with diffraction peak intensity as color map) during in situ XRD upon heating and reduction in $\mathrm{H}_{2}$, illustrating the complex pathway to CoCrFeNi HEA alloy formation

microstructure allows to apply knowledge in microstructureproperty relationships obtained in HEAs via conventional processing routes, combined with the geometrical freedom and complexity offered by AM. Residual sub-micrometer porosity and swelling voids observed for the $3 \mathrm{D}$ ink-extruded material are telltale features of the sintering process (Fig. 4a). With increasing sintering temperature, higher densification is achieved for a sintering time of $1 \mathrm{~h}$. No significant difference is observed between filaments extruded from nozzles spanning 200 to $510 \mu \mathrm{m}$ in diameter, demonstrating the ability of the process to create components with variable wall or strut thicknesses (Supplementary Figure 4). The maximum density achieved is $99.6 \pm$ $0.1 \%$ for sintering at $1573 \mathrm{~K}$ for $1 \mathrm{~h}$, averaged over all nozzle diameters. This is substantially higher compared to prior work on pre-alloyed CoCrFeMnNi powders, where $87 \%$ was achieved upon pressure-less sintering of loose powder, and $97 \%$ for electron-beam melting of powder beds. Only spark plasma sintering yields comparable densities to the sintered HEA of this work $^{43}$. The sintering mechanism of mechanically-alloyed $\mathrm{CoCrFeNi}$ with a grain size of $<20 \mu \mathrm{m}$ was found to be dominated by $\mathrm{Co}$ and Ni diffusion ${ }^{44}$. Based on the in situ XRD data of our work, $\mathrm{Ni}$ and $\mathrm{Co}$ are the first metals to appear upon coreduction and thus initiate densification upon sintering of inkextruded $\mathrm{CoCrFeNi}$ filaments. For flaw-sensitive mechanical applications, hot isostatic pressing could be applied to completely eliminate the small residual closed porosity. The slight isothermal swelling phenomenon observed at $1573 \mathrm{~K}$ is attributed to diffusion of freshly reduced $\mathrm{Cr}$ into the surrounding metallic matrix, thereby expanding its lattice parameter, as seen by XRD, and the overall volume ${ }^{45}$ (Fig. 4b).

Fully sintered filaments $(1573 \mathrm{~K}, 1 \mathrm{~h})$, with a nearly circular cross-section and a grain size of 35-80 $\mu \mathrm{m}$, an average diameter of $125 \mu \mathrm{m}$ and a gauge length of $10 \mathrm{~mm}$, were tested in tension until fracture. The stress-strain curves are repeatable, showing a yield strength of $250 \pm 5 \mathrm{MPa}$, extensive strain hardening and an ultimate tensile strength of $598 \pm 8 \mathrm{MPa}$ at $33.8 \pm 1.3 \%$ fracture strain at $293 \mathrm{~K}$ (Fig. 4c). At $130 \mathrm{~K}$, the yield stress, ultimate tensile strength and fracture strain are all increased to $388 \pm 7 \mathrm{MPa}$, $864 \pm 12 \mathrm{MPa}$, and $37.6 \pm 0.7 \%$, respectively, demonstrating the outstanding combination of strength and ductility of CoCrFeNi at cryogenic temperatures. While yield and ultimate strengths are comparable to, or exceed, properties of cast CoCrFeNi (Supplementary Table 1$)^{46-48}$, elongation to fracture is reduced; this is consistent with the small number of grains across the filament diameter (2-3 grains based on a grain size of $35-80 \mu \mathrm{m})$, which is an effect also observed for $\mathrm{Al}_{0.25} \mathrm{CoCrFeNi}$ coarse-grained $(\sim 100 \mu \mathrm{m})$ sheets upon reduction of their thickness ${ }^{49}$. In general, the measured yield stress in this work is expected to be lower compared to the bulk value due to the small number of grains across the filament diameter and thus reduced constraint strengthening ${ }^{50}$. Upon testing of filaments with a reduced gauge length of $1 \mathrm{~mm}$, the stress-strain curves exhibit more variability, which is consistent with oligo-crystalline behavior: serrations and jumps in the stress-strain curves indicate activation and subsequent hardening of slip systems in individual grains with favorable orientations, thus affecting yield stress and ductility. 

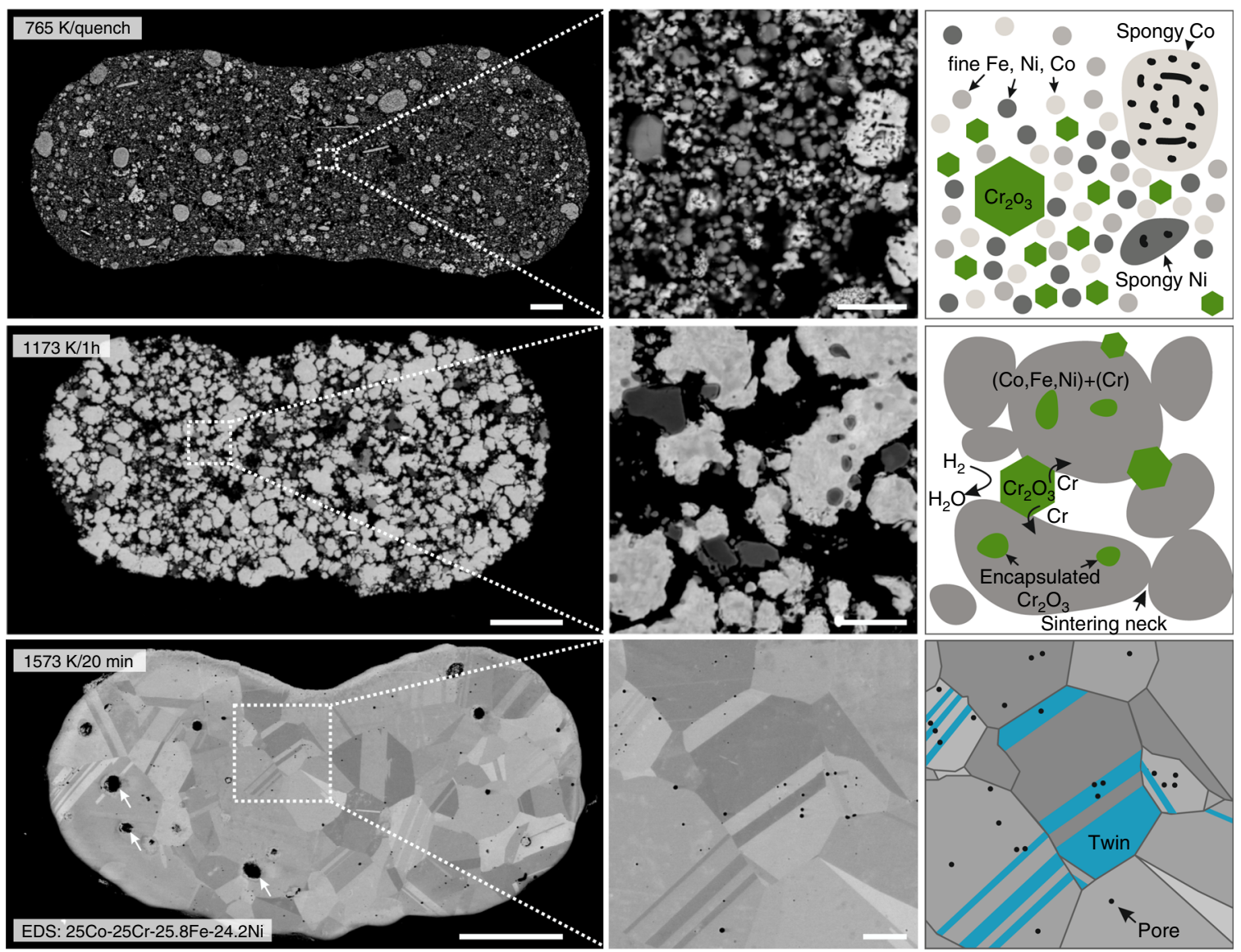

Fig. 3 Microstructural evolution of 3D extrusion printed $\mathrm{CoCrFeNi} \mathrm{HEA} \mathrm{filaments.} \mathrm{top)} \mathrm{Cross-section} \mathrm{of} \mathrm{a} 3 \mathrm{D}$ extruded filament heated to $765 \mathrm{~K}$ in $\mathrm{H}_{2}$ and quenched in $\mathrm{Ar}$. A fine structure of metallic $\mathrm{Fe}, \mathrm{Ni}$ and $\mathrm{Co}$ with inter-dispersed $\mathrm{Cr}_{2} \mathrm{O}_{3}$ is observed (right). center) Filament sintered at $1173 \mathrm{~K}$ for $1 \mathrm{~h}$ showing sintering of the ( $\mathrm{Co}, \mathrm{Fe}, \mathrm{Ni}, \mathrm{Cr}$ )-matrix leading to partial encapsulation of $\mathrm{Cr}_{2} \mathrm{O}_{3}$ (right). Smaller $\mathrm{Cr}_{2} \mathrm{O}_{3}$ particles were reduced to $\mathrm{Cr}$ and dissolved (Supplementary Figure 3). bottom) CoCrFeNi HEA filament sintered at $1573 \mathrm{~K}$ for 20 min showing a coarsened grain structure (grain size of 5 to $25 \mu \mathrm{m}$ ) with annealing twins, swelling voids $(\sim 2-5 \mu \mathrm{m}$, arrows) and sub-micrometer pores. Filaments are flattened due to printing on a substrate and gravitational sagging. Scale bars are $25 \mu \mathrm{m}$ for low magnification (left) and $3 \mu \mathrm{m}$ for high magnification (center) micrographs

Additionally, the reduced gauge length increases the sensitivity for localized effects such as necking before fracture (Supplementary Figure 5). The fracture mode is ductile and dimples on the fracture surface are indicative of ductile void coalescence (Fig. 4c, inset). This result is in contrast to recent observations made for $\mathrm{CoCrFeNi}$ tensile specimens charged in $120 \mathrm{MPa}_{2}$ gas, where a change in fracture mode to intergranular fracture was observed ${ }^{51}$. However, increased ductility and strength of electrochemically $\mathrm{H}_{2}$-charged CoCrFeMnNi HEA tensile specimens have also been described $^{52}$. No such transition is observed for our CoCrFeNi filaments after sintering at $1573 \mathrm{~K}$ for $1 \mathrm{~h}$ and furnace cooling in pure $\mathrm{H}_{2}$ at ambient pressure: ductile behavior is prevalent over the complete fracture surface (Supplementary Figure 6). Submicrometer oxide precipitates observed in the dimples are measured by EDS to be rich in $\mathrm{Si}, \mathrm{Ca}, \mathrm{Mg}, \mathrm{Al}$, and $\mathrm{Na}$ : these elements were present as impurities in the original oxides and were not reduced to metal.

The load-bearing capability of complex-shaped 3D inkextruded $\mathrm{CoCrFeNi}$ specimens is further demonstrated by compression testing at 77 and $293 \mathrm{~K}$ of a $0 / 90^{\circ}$ cross-ply microlattices with a solid volume fractions of $25 \%(103 \pm 12 \mu \mathrm{m}$ diameter wide struts with $363 \pm 17 \mu \mathrm{m}$ center-to-center spacing) to $63 \%(285 \pm 38 \mu \mathrm{m}$ diameter wide struts with $498 \pm 23 \mu \mathrm{m}$ center-to-center spacing) (Fig. 4d). Due to stress concentrations at strut contact points, the micro-lattices have a narrow elastic range, beyond which they undergo stretching-dominated plastic deformation with continuously-increasing stress up to a strain of 50\%; at higher strains, the cross-ply stacked structure of struts densifies due to plastic collapse of vertical inter-strut channels. Throughout the compressive deformation, the lattices show no signs of catastrophic cracking or abrupt loss in strength (stress serrations) up to their compaction above $50 \%$ strain, demonstrating high energy absorption and an outstanding combination of strength and ductility (Supplementary Movie 1). Direct comparison of two lattices, with an identical relative density of $60 \%$, tested at 77 and $293 \mathrm{~K}$, reveals a higher yield stress and a higher strain hardening rate at $77 \mathrm{~K}$, combined with excellent ductility. This combined effect yields higher energy absorption (area under the stress-strain curve) at $77 \mathrm{~K}$ compared to $293 \mathrm{~K}$.

AM of HEAs via directed-energy melting/sintering of prealloyed powders is an emerging field; the approach presented here is a low-cost alternative method, based on ambient-temperature ink-printing of inexpensive oxides, followed by hydrogen reduction and sintering, which yields compositionally-homogeneous, dense, strong, ductile HEA filaments or 3D structures. The use of blended powders-oxide as shown here, but which could be also metallic-allows full compositional flexibility well beyond the particular $\mathrm{CoCrFeNi}$ composition studied here, and even compositionally-graded HEAs, which can be printed by changing the mixing ratios of multiple inks. This will also allow this 

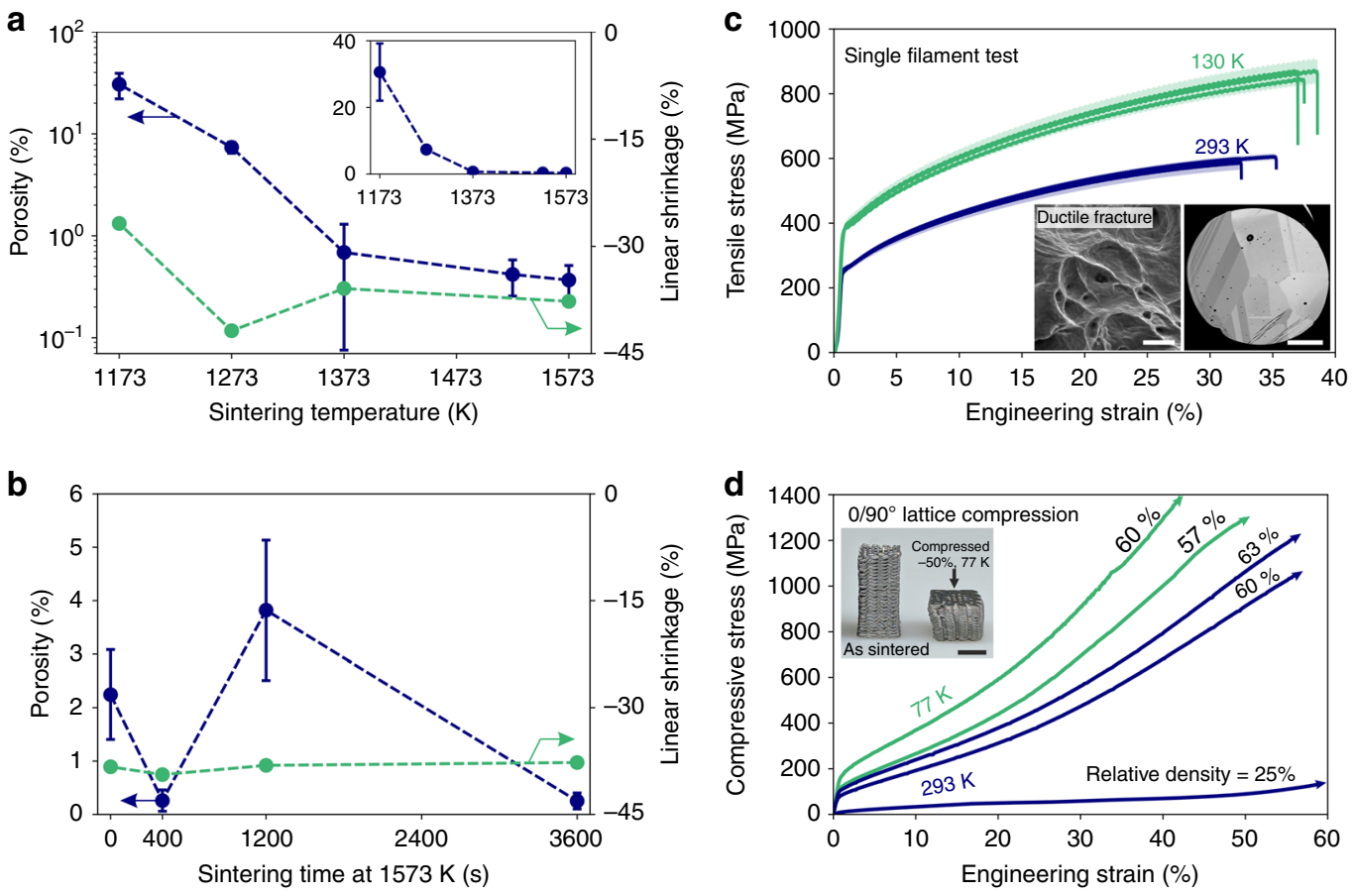

Fig. 4 Porosity evolution and mechanical performance of extrusion-printed $250 \mu \mathrm{m}$ CoCrFeNi HEA filaments. a Evolution of porosity (logarithmic scale, blue) and shrinkage (linear scale, green) with increasing sintering temperature in $\mathrm{H}_{2}$ for $1 \mathrm{~h}$ dwell time. Extensive, reproducible linear shrinkage is observed, with a maximum at $1273 \mathrm{~K}$. Averaged data over all nozzle diameters. Inset: Porosity on a linear scale for comparison. Error bars correspond to $\pm \sigma$. b Evolution of porosity and shrinkage (both linear scale) with sintering time at $1573 \mathrm{~K} \mathrm{in} \mathrm{H}_{2}$. Error bars correspond to $\pm \sigma$. c Engineering stress-strain curves of single filaments ( $125 \mu \mathrm{m}$ average diameter, $10 \mathrm{~mm}$ gauge length, from $250 \mu \mathrm{m}$ nozzle, sintered at $1573 \mathrm{~K} / 1 \mathrm{~h}$ ) tested in tension at $130 \mathrm{~K}$ (green line) and $293 \mathrm{~K}$ (blue line) until fracture. Shading corresponds to the $1 \sigma$ error in calculated stress based on the measured cross-sectional area variation of filaments. Inset: fracture surface showing dimples typical of ductile fracture mode at $293 \mathrm{~K}$ (scale bar $1 \mu \mathrm{m}$ ) and cross-section of a filament showing its oligocrystalline structure (grain size: $35-80 \mu \mathrm{m}$ ). Scale bar is $25 \mu \mathrm{m}$. d Compressive stress-strain curve of $0 / 90^{\circ} \mathrm{cross}-\mathrm{ply}$ CoCrFeNi HEA micro-lattices with $25 \%$ (when extruded with a $200 \mu \mathrm{m}$ nozzle) to $63 \%$ ( $250 \mu \mathrm{m}$ nozzle) relative density, sintered at $1573 \mathrm{~K}$ for $1 \mathrm{~h}$, and tested at $77 \mathrm{~K}$ (green) and $293 \mathrm{~K}$ (blue), showing extensive plastic deformation at all temperatures. All tests were interrupted prior to fracture. Inset: Sintered lattice before (left) and after (right) compression to $-50 \%$ at $77 \mathrm{~K}$, showing homogeneous deformation. Scale bar is $2 \mathrm{~mm}$

technique to be used in alloy development by creating a variety of compositions, in short times, for combinatorial discovery of novel alloys, as demonstrated using beam-based deposition of metal powder blends ${ }^{53}$. Additionally, this method can create many other printed micro-lattice geometries ${ }^{18}$ and the $3 \mathrm{D}$ ink-extruded structures can be modified in their green body state, as demonstrated by creating origami and kirigami structures from ink-extruded $\mathrm{TiH}_{2}$ sheets ${ }^{19}$. The CoCrFeNi HEA produced here can find direct applications in low-temperature applications requiring high ductility and fracture toughness, based on the unique properties of the $\mathrm{CoCrFe}(\mathrm{Mn}) \mathrm{Ni} \mathrm{HEA}$ at cryogenic temperatures ${ }^{42}$. Combined with the geometrical freedom of extrusion printing to create micro-lattices at low cost, this material-process combination could be scaled up for high-volume production of light-weight, high-ductility, impact-absorbing HEA structures than can operate at temperatures ranging from liquid nitrogen up to $\sim 1000^{\circ} \mathrm{C}$, or even beyond, if coatings are used, e.g., via pack aluminization. With recent advances in AM using lithography and direct laser writing techniques, sub-micron scale lattices forming metamaterials ${ }^{54}$ and HEA-polymer composites ${ }^{12}$ showing superior mechanical properties have been demonstrated. Thus miniaturization of HEA cellular structures provides a potential path to discovery of combinations of structures and alloys further pushing the limits of their mechanical performance beyond the-already impressive-bulk properties of HEAs. The approach presented in this work, co-reduction of blended oxide nanopowder inks, allows to create such complex composites or purely metallic HEA micro- and nano-lattices.

\section{Methods}

Ink preparation, 3D printing, and thermal treatment. The extrudable ink (target composition after co-reduction: $25 \mathrm{Co}-25 \mathrm{Cr}-25 \mathrm{Fe}-25 \mathrm{Ni}$, at.\%) with $70: 30$ vol.\% powder-to-polymer ratio is prepared from $\mathrm{Fe}_{2} \mathrm{O}_{3}(2.57 \mathrm{~g}, \geq 99 \%,<5 \mu \mathrm{m}$, SigmaAldrich), $\mathrm{NiO}$ (2.40 g, 99\%, -325 mesh, Sigma-Aldrich), $\mathrm{Co}_{3} \mathrm{O}_{4}(2.58 \mathrm{~g},<10 \mathrm{um}$ Sigma-Aldrich) and $\mathrm{Cr}_{2} \mathrm{O}_{3}(2.45 \mathrm{~g}, 99.7 \%,-325$ mesh, Alfa Aesar) powders, polylactic-co-glycolic-acid (PLGA, $0.87 \mathrm{~g}, 82: 18$, Evonik Industries) as binder, dibutyl phthalate (DBP, $1.58 \mathrm{~g}$, Sigma-Aldrich) as plasticizer, ethylene glycol butyl ether (EGBE, $0.79 \mathrm{~g}$, Sigma-Aldrich) as surfactant and methylene chloride ( $20 \mathrm{ml}$, DCM, Sigma-Aldrich) as solvent. Wet mill-mixing of the oxide powder is performed with $8 \mathrm{ml} \mathrm{DCM}$ and EGBE for $30 \mathrm{~min}$ (WC-Co, ball-to-powder ratio: 2.15) and then combined with the dissolved PLGA and DBP. The low viscosity ink is thickened by solvent evaporation to a viscosity of $\sim 40 \mathrm{~Pa}$ s. Extrusion printing is performed on an Envisiontec 3D Bio-plotter using tapered plastic nozzles (200 and $250 \mu \mathrm{m}$, Nordson EFD) and straight metal nozzles (330 and $510 \mu \mathrm{m}$, Nordson EFD). Extruded filaments are co-reduced and sintered in flowing $\mathrm{H}_{2}$ (99.999\%, dew point: $201 \mathrm{~K}, 250 \mathrm{ml} \mathrm{min}^{-1}$, Airgas) in a commercial $\mathrm{H}_{2}$ tube furnace $\left(10 \mathrm{~K} \mathrm{~min}^{-1}\right.$, GSL1500-50HG, MTI) in alumina boats. De-binding was performed in two $30 \mathrm{~min}$ steps at 150 and $300^{\circ} \mathrm{C}$.

In situ X-ray diffraction. In situ X-ray diffraction during heating $\left(10 \mathrm{~K} \mathrm{~min}^{-1}\right)$ in reducing $\mathrm{H}_{2}$ atmosphere $\left(99.9999 \%, 1.3 \mathrm{ml} \mathrm{min}^{-1}\right)$ is performed with a monochromatic beam $(19.9 \mathrm{keV}, 0.7 \times 1.4 \mathrm{~mm})$ at the Material Science powder diffraction beamline X04SA ${ }^{55}$ of the Swiss Light Source (Paul Scherrer Institut, Switzerland). The as-printed filament segment $(2 \mathrm{~mm}$ in length and $250 \mu \mathrm{m}$ in diameter) is contained in a $500 \mu \mathrm{m}$ outer diameter quartz capillary with $10 \mu \mathrm{m}$ wal thickness (Hilgenberg, Germany), which is cut and joined on both ends to stainless steel tubing using epoxy adhesive (Araldite Rapid, Huntsman). A gas-tight connection is achieved by a compression fitting (Swagelok, USA) with graphite ferrules. Heating is realized by a hot-air blower (Cyberstar, France) located under the quartz tube (Supplementary Figure 7). The hot blower gas temperature at the specimen position is calibrated prior to diffraction runs over the complete temperature range by placing a thermocouple instead of the specimen. Diffracted 
intensities are recorded on a Mythen II array simultaneously covering $120^{\circ}$ of $2 \theta$, at an exposure time of $24 \mathrm{~s}$ and $3^{\circ}$ rocking angle to increase particle statistics. Silicon powder (NIST 640c) is used as calibration standard at room temperature. Data post-processing and plotting are performed using Python (Anaconda, Continuum Analytics). Perceptually uniform color maps are retrieved from the cmocean package $^{56}$. All diffractograms are background-corrected using asymmetric least squares smoothing ${ }^{57}$.

Characterization. The mass loss of milled feedstock powder without binder addition is measured by thermogravimetry $\left(99.999 \% \mathrm{H}_{2}, 100 \mathrm{ml} \mathrm{min}^{-1}, 10 \mathrm{~K} \mathrm{~min}^{-1}, \mathrm{Al}_{2} \mathrm{O}_{3}\right.$ crucible, Netzsch STA 449F5). Tensile testing of reduced, sintered HEA single filaments with an average diameter of $125 \mu \mathrm{m}$ is performed on a RSA-G2 (TA Instruments, USA) mechanical analyzer with gauge lengths of 1 and $10 \mathrm{~mm}$ using a $35 \mathrm{~N}$ load cell (Supplementary Figure 8). Compressive testing of a 3D-printed, reduced and sintered HEA lattices (25\%: $5 \times 5 \times 2.6 \mathrm{~mm}, 200 \mu \mathrm{m}$ nozzle; $57-63 \%: 2.75 \times 2.75 \times$ $6 \mathrm{~mm}, 250 \mu \mathrm{m}$ nozzle) is performed on a Sintech $20 \mathrm{G}$ (MTS, USA) with a $100 \mathrm{kN}$ load cell. All experiments are performed at an initial strain rate of $5 \times 10^{-4} \mathrm{~s}^{-1}$. Specimens for microscopic cross-section analysis are embedded into epoxy mounting resin (Epothin2, Buehler, USA), ground with SiC grinding paper (P600 to P2500), polished using 6,3 , and $1 \mu \mathrm{m}$ diamond suspensions, and lapped with colloidal silica. Scanning electron microscopy is performed on a FEI Quanta 650 equipped with an Oxford EDX detector on carbon-coated, lapped specimens. Oxide powder specimens are coated with $8 \mathrm{~nm}$ Os. Porosity is measured using thresholding in ImageJ. Linear shrinkage is calculated from longitudinal filament size measurements taken prior and after sintering. 2D X-ray diffraction on milled $\mathrm{Co}_{3} \mathrm{O}_{4}+\mathrm{Cr}_{2} \mathrm{O}_{3}+\mathrm{Fe}_{2} \mathrm{O}_{3}+\mathrm{NiO}$ feedstock powder prior and after TGA is performed on a Bruker KAPPA APEX II with a Mo source.

\section{Data availability}

The data that support the findings of this study are available from the corresponding author upon reasonable request.

Received: 18 October 2018 Accepted: 25 January 2019

Published online: 22 February 2019

\section{References}

1. Gorsse, S., Hutchinson, C., Gouné, M. \& Banerjee, R. Additive manufacturing of metals: a brief review of the characteristic microstructures and properties of steels, Ti-6Al-4V and high-entropy alloys. Sci. Technol. Adv. Mater. 18, 584-610 (2017).

2. Li, X. Additive manufacturing of advanced multi-component alloys: bulk metallic glasses and high entropy alloys. Adv. Eng. Mater. 20, 1700874 (2018).

3. Brif, Y., Thomas, M. \& Todd, I. The use of high-entropy alloys in additive manufacturing. Scr. Mater. 99, 93-96 (2015).

4. Miracle, D. B. \& Senkov, O. N. A critical review of high entropy alloys and related concepts. Acta Mater. 122, 448-511 (2017).

5. Fujieda, T. et al. First demonstration of promising selective electron beam melting method for utilizing high-entropy alloys as engineering materials. Mater. Lett. 159, 12-15 (2015).

6. Kunce, I., Polanski, M., Karczewski, K., Plocinski, T. \& Kurzydlowski, K. J. Microstructural characterisation of high-entropy alloy AlCoCrFeNi fabricated by laser engineered net shaping. J. Alloy. Compd. 648, 751-758 (2015).

7. Joseph, J., Stanford, N., Hodgson, P. \& Fabijanic, D. M. Tension/compression asymmetry in additive manufactured face centered cubic high entropy alloy. Scr. Mater. 129, 30-34 (2017).

8. Shiratori, H. et al. Relationship between the microstructure and mechanical properties of an equiatomic AlCoCrFeNi high-entropy alloy fabricated by selective electron beam melting. Mater. Sci. Eng. A 656, 39-46 (2016).

9. Ocelík, V., Janssen, N., Smith, S. N. \& De Hosson, J. T. M. Additive manufacturing of high-entropy alloys by laser processing. JOM 68, 1810-1818 (2016).

10. Piglione, A. et al. Printability and microstructure of the CoCrFeMnNi highentropy alloy fabricated by laser powder bed fusion. Mater. Lett. 224, 22-25 (2018).

11. Kunce, I., Polanski, M. \& Bystrzycki, J. Structure and hydrogen storage properties of a high entropy ZrTiVCrFeNi alloy synthesized using laser engineered net shaping (LENS). Int. J. Hydrog. Energy 38, 12180-12189 (2013).

12. Zhang, X. et al. Three-dimensional high-entropy alloy-polymer composite nanolattices that overcome the strength-recoverability trade-off. Nano. Lett. 18, 4247-4256 (2018).

13. Tang, Y., Zhou, Y., Hoff, T., Garon, M. \& Zhao, Y. F. Elastic modulus of 316 stainless steel lattice structure fabricated via binder jetting process. Mater. Sci. Technol. 32, 648-656 (2016).
14. Bai, Y. \& Williams, C. B. An exploration of binder jetting of copper. Rapid Prototyp. J. 21, 177-185 (2015).

15. Hong, D. et al. Binder-jetting 3D printing and alloy development of new biodegradable Fe-Mn-Ca/Mg alloys. Acta Biomater. 45, 375-386 (2016).

16. Dilip, J. J. S., Miyanaji, H., Lassell, A., Starr, T. L. \& Stucker, B. A novel method to fabricate TiAl intermetallic alloy $3 \mathrm{D}$ parts using additive manufacturing. Def. Technol. 13, 72-76 (2017).

17. Caputo, M. P. \& Solomon, C. V. A facile method for producing porous parts with complex geometries from ferromagnetic Ni-Mn-Ga shape memory alloys. Mater. Lett. 200, 87-89 (2017).

18. Jakus, A. E., Taylor, S. L., Geisendorfer, N. R., Dunand, D. C. \& Shah, R. N Metallic architectures from 3D-Printed powder-based liquid inks. Adv. Funct. Mater. 25, 6985-6995 (2015).

19. Ahn, B. Y. et al. Printed origami structures. Adv. Mater. 22, 2251-2254 (2010).

20. Lewis, J. A. Direct ink writing of 3D functional materials. Adv. Funct. Mater. 16, 2193-2204 (2006).

21. Skylar-Scott, M. A., Gunasekaran, S. \& Lewis, J. A. Laser-assisted direct ink writing of planar and 3D metal architectures. Proc. Natl Acad. Sci. 113, 6137-6142 (2016)

22. Yetna N'Jock, M. et al. Characterization of $100 \mathrm{Cr} 6$ lattice structures produced by robocasting. Mater. Des. 121, 345-354 (2017).

23. Taylor, S. L., Jakus, A. E., Shah, R. N. \& Dunand, D. C. Iron and nickel cellular structures by sintering of 3D-printed oxide or metallic particle inks. Adv. Eng. Mater. 19, 1600365 (2006).

24. Taylor, S. L., Shah, R. N. \& Dunand, D. C. Ni-Mn-Ga micro-trusses via sintering of 3D-printed inks containing elemental powders. Acta Mater. 143, 20-29 (2018).

25. Taylor, S. L., Ibeh, A. J., Jakus, A. E., Shah, R. N. \& Dunand, D. C. NiTi-Nb micro-trusses fabricated via extrusion-based 3D-printing of powders and transient-liquid-phase sintering. Acta Biomater. 76, 359-370 (2018).

26. Calvo, M., Jakus, A. E., Shah, R. N., Spolenak, R. \& Dunand, D. C. Microstructure and processing of $3 \mathrm{D}$ printed tungsten microlattices and infiltrated W-Cu composites. Adv. Eng. Mater. 20, 1800354 (2018).

27. Taylor, S. L., Shah, R. N. \& Dunand, D. C. Microstructure and porosity evolution during sintering of Ni-Mn-Ga wires printed from inks containing elemental powders. Intermetallics 104, 113-123 (2019).

28. Chu, W. F. \& Rahmel, A. The kinetics of the reduction of chromium oxide by hydrogen. Metall. Trans. B 10, 401-407 (1979).

29. Zhang, Y., Wei, W., Yang, X. \& Wei, F. Reduction of Fe and Ni in Fe-Ni-O systems. J. Min. Metall. Sect. B Metall. 49, 13-20 (2013).

30. Brocchi, E. A., Moura, F. J. \& Macedo de, D. W. Synthesis and characterisation of nanostructured Ni-Co alloy Part 3: $\mathrm{NiO}$ and $\mathrm{Co} 3 \mathrm{O} 4$ coformed reduction kinetics. Miner. Process. Extr. Metall. 118, 44-48 (2009).

31. Takano, C., Zambrano, A. P., Nogueira, A. E. A., Mourao, M. B. \& Iguchi, Y Chromites reduction reaction mechanisms in carbon-chromites composite agglomerates at $1773 \mathrm{~K}$. ISIJ Int. 47, 1585-1589 (2007).

32. Radomysel'skii, I. D., Barshohevskaya, L. F. \& Dzykovich, I. Y. Process of coreduction of iron and chromium oxides with hydrogen. Sov. Powder Metall. Met. Ceram. 10, 255-259 (1971).

33. Bracconi, P. \& Dufour, L. C. Hydrogen reduction of cobalt-chromium spinel oxides. I. Stoichiometric cobalt chromite. J. Phys. Chem. 79, 2395-2400 (1975).

34. Zhang, Y., Liu, Y. \& Wei, W. Products of carbothermic reduction of Fe-Cr-O and $\mathrm{Fe}-\mathrm{Cr}-\mathrm{Ni}-\mathrm{O}$ systems. Trans. Nonferrous Met. Soc. China 24, 1210-1219 (2014).

35. Cochran, J. K., Lee, K. J. \& Sanders, T. H. Metallic articles formed by reduction of nonmetallic articles and method of producing metallic articles. Patent US6582651B1 (2003).

36. Shamblen, C. E., Woodfield, A. P., Ott, E. A. \& Gigliotti, M. F. X. Method for fabricating a martensitic steel without any melting. Patent US7553383B2 (2009).

37. Church, B. C., Sanders, T. H., Speyer, R. F. \& Cochran, J. K. Interconnect thermal expansion matching to solid oxide fuel cells. J. Mater. Sci. 40, 4893-4898 (2005).

38. Nadler, J. H., Sanders, T. H. \& Speyer, R. F. Oxide reduction and sintering of Fe-Cr alloy honeycombs. J. Mater. Res. 18, 1787-1794 (2003).

39. Chou, H.-P., Chang, Y.-S., Chen, S.-K. \& Yeh, J.-W. Microstructure, thermophysical and electrical properties in AlxCoCrFeNi $(0 \leq x \leq 2)$ highentropy alloys. Mater. Sci. Eng. B 163, 184-189 (2009).

40. Laplanche, G. et al. Elastic moduli and thermal expansion coefficients of medium-entropy subsystems of the $\mathrm{CrMnFeCoNi}$ high-entropy alloy. J. Alloy. Compd. 746, 244-255 (2018).

41. Dahlborg, U. et al. Structure of some CoCrFeNi and CoCrFeNiPd multicomponent HEA alloys by diffraction techniques. J. Alloy. Compd. 681 , 330-341 (2016)

42. Gludovatz, B. et al. A fracture-resistant high-entropy alloy for cryogenic applications. Science 345, 1153-1158 (2014). 
43. Eißmann, N., Klöden, B., Weißgärber, T. \& Kieback, B. High-entropy alloy CoCrFeMnNi produced by powder metallurgy. Powder Metall. 60, 184-197 (2017).

44. Mane, R. B. \& Panigrahi, B. B. Sintering mechanisms of mechanically alloyed CoCrFeNi high-entropy alloy powders. J. Mater. Res. 33, 3321-3329 (2018).

45. Böhm, A. \& Kieback, B. Investigation of swelling behaviour of Ti-Al elemental powder mixtures during reaction sintering. Z. Met. 89, 90-95 (1998).

46. Huo, W. et al. Remarkable strength of CoCrFeNi high-entropy alloy wires at cryogenic and elevated temperatures. Scr. Mater. 141, 125-128 (2017).

47. Huo, W. et al. Strain-rate effect upon the tensile behavior of CoCrFeNi highentropy alloys. Mater. Sci. Eng. A 689, 366-369 (2017).

48. Huang, T. et al. Effect of carbon addition on the microstructure and mechanical properties of $\mathrm{CoCrFeNi}$ high entropy alloy. Sci. China Technol. Sci. 61, 117-123 (2018).

49. Hou, J. et al. Deformation behavior of Al0.25CoCrFeNi high-entropy alloy after recrystallization. Metals 7, 111 (2017).

50. Armstrong, R. W. On size effects in polycrystal plasticity. J. Mech. Phys. Solids 9, 196-199 (1961).

51. Nygren, K. E. et al. Hydrogen embrittlement of the equi-molar FeNiCoCr alloy. Acta Mater. 157, 218-227 (2018).

52. Luo, H., Li, Z. \& Raabe, D. Hydrogen enhances strength and ductility of an equiatomic high-entropy alloy. Sci. Rep. 7, 9892 (2017).

53. Haase, C., Tang, F., Wilms, M. B., Weisheit, A. \& Hallstedt, B. Combining thermodynamic modeling and 3D printing of elemental powder blends for high-throughput investigation of high-entropy alloys-towards rapid alloy screening and design. Mater. Sci. Eng. A 688, 180-189 (2017).

54. Li, X. \& Gao, H. Mechanical metamaterials: smaller and stronger. Nat. Mater. 15, 373-374 (2016).

55. Willmott, P. R. et al. The materials science beamline upgrade at the swiss light source. J. Synchrotron Radiat. 20, 667-682 (2013).

56. Thyng, K., Greene, C., Hetland, R., Zimmerle, H. \& DiMarco, S. True colors of oceanography: guidelines for effective and accurate colormap selection. Oceanography 29, 9-13 (2016).

57. Eilers, P. H. \& Boelens, H. F. Baseline correction with asymmetric least squares smoothing. Leiden. Univ. Med. Cent. Rep. 1, 5 (2005).

\section{Acknowledgements}

C.K. received funding from the Swiss National Science Foundation as an Early Postdoc Mobility fellowship under grant No. 172180. The authors thank the Paul Scherrer Institut, Villigen, Switzerland for the provision of beamtime at the X04SA beamline of the Swiss Light Source, Dr. A. Pinar for providing the gas capillary system, and M. Lange for technical support. We gratefully acknowledge Prof. R. Shah for useful discussion and access to her Bioplotter for 3D printing and Prof. S. Haile and Dr. T. Davenport for the TGA measurements. This work made use of the EPIC facility of Northwestern
University's NUANCE Center and the IMSERC, which have received support from the Soft and Hybrid Nanotechnology Experimental (SHyNE) Resource (NSF ECCS1542205); the State of Illinois and International Institute for Nanotechnology (IIN). This work made use of the Central Laboratory for Materials Mechanical Properties and the MatCI Facility that together with EPIC received support from the MRSEC program (NSF DMR-1720139) at the Materials Research Center.

\section{Author contributions}

C.K. and D.C.D. conceived the project. N.P.M.C. prepared, and together with C.K. performed, the in situ XRD experiments. C.K. performed all other experiments and evaluated the data. All authors discussed the findings and contributed to writing of the manuscript.

\section{Additional information}

Supplementary Information accompanies this paper at https://doi.org/10.1038/s41467019-08763-4.

Competing interests: The authors declare no competing interests.

Reprints and permission information is available online at http://npg.nature.com/ reprintsandpermissions/

Journal peer review information: Nature Communications thanks Xiaoyan Li and the other anonymous reviewer(s) for their contribution to the peer review of this work. Peer reviewer reports are available.

Publisher's note: Springer Nature remains neutral with regard to jurisdictional claims in published maps and institutional affiliations.

Open Access This article is licensed under a Creative Commons Attribution 4.0 International License, which permits use, sharing, adaptation, distribution and reproduction in any medium or format, as long as you give appropriate credit to the original author(s) and the source, provide a link to the Creative Commons license, and indicate if changes were made. The images or other third party material in this article are included in the article's Creative Commons license, unless indicated otherwise in a credit line to the material. If material is not included in the article's Creative Commons license and your intended use is not permitted by statutory regulation or exceeds the permitted use, you will need to obtain permission directly from the copyright holder. To view a copy of this license, visit http://creativecommons.org/ licenses/by/4.0/.

(C) The Author(s) 2019 